\title{
Rolling Circle Enzymatic Replication of a Complex Multi- Crossover DNA Nanostructure
}

\author{
Chenxiang Lin ${ }^{1}$, Xing Wang ${ }^{2}$, Yan Liu ${ }^{1}$, Nadrian C. Seeman ${ }^{2, *}$, and Hao Yan ${ }^{1, *}$ \\ ${ }^{1}$ Department of Chemistry and Biochemistry \& The Biodesign Institute, Arizona State University, \\ Tempe, AZ 85287 \\ 2Department of Chemistry, New York University, New York, New York, 10003
}

\section{Abstract}

Nature has evolved replicable biological molecules, such as DNA, as genetic information carriers. The replication process is tightly controlled by complicated cellular machinery. It is interesting to ask if artificial DNA nano-objects with a complex secondary structure can be replicated in the same way as simple DNA double helices. Here we demonstrate that paranemic crossover DNA, a structurally complicated multi-crossover DNA molecule, can be replicated successfully using Rolling Circle Amplification (RCA). The amplification efficiency is moderate with high fidelity, confirmed by native PAGE, thermal transition study and Ferguson analysis. The structural details of the DNA structure after the full replication circle are verified by hydroxyl radical autofootprinting. We conclude that RCA can serve as a reliable method to replicate complex DNA structures. We also discuss the possibility of using viruses and bacteria to clone artificial DNA nano-objects. The findings that single stranded paranemic crossover DNA molecules can be replicated by DNA polymerase will not only be useful in nanotechnology, but may have implications for the possible existence of such complicated DNA structures in nature.

\section{Keywords}

Paranemic crossover DNA; Rolling-circle amplification; DNA nanotechnology

\section{Introduction}

The central dogma of molecular biology depicts the biological information flow that applies to all known forms of life. DNA replication is one of the most fundamental and important activities in the cell that ensures the correct transmission of genetic information from generation to generation. Nowadays, DNA is not only regarded as the carrier of genetic codes for life, but also as a generic building material for nano-structures. Numerous artificial DNA nano-objects of various geometry and topology have been built through DNA selfassembly. ${ }^{1-5}$ It is interesting to ask if such complicated structured artificial DNA nanoobjects can be replicated. In living cells, a number of sophisticated molecular machines work cooperatively to facilitate the efficient and precise replication of each strand of linear duplex DNA. Many of the enzymes involved have been shown to work outside of the cellular environment. This fact suggests that it is possible to utilize enzymatic methods to replicate artificial DNA structures. The main challenge here for the non-natural system is to

\footnotetext{
*Address correspondence to hao.yan@asu.edu; ned.seeman@nyu.edu.

Supporting Information Available on the DNA sequences used in this work. This material is available free of charge via the Internet at http://pubs.acs.org.
} 
overcome the difficulties generated by the complicated secondary structures of the DNA nano-objects, which are believed not to exist commonly in nature.

Previous successes in replicating artificial DNA structures have been very limited but inspiring. ${ }^{6-8}$ Von Kiedrowski and colleagues used a chemical method to replicate a threebranch star motif in which three DNA strands are connected by a chemical linker. ${ }^{6}$ Shih et al have designed a DNA octahedron that assembled from one clonable heavy chain $(\sim 1.7 \mathrm{~kb})$ and five light chains. ${ }^{7}$ The heavy chain was ligated into a plasmid and amplified in bacteria. Its single stranded form is obtained by insertion of a nick endonuclease recognition site and digested by restriction after amplification. Although the heavy chain can be folded into a loosely connected structure, it does not form a complete nano-object without the help of the light chains. We have recently reported the replication of a DNA nano-junction with high efficiency and fidelity by rolling-circle amplification (RCA), which offers a potentially general method for enzymatic amplification of DNA nano-structures. ${ }^{8}$ However, the DNA junction (a 4-arm DNA junction) amplified there had a relatively simple structure.

Therefore, the following important questions remained open: [1] can RCA replicate DNA nano-objects with more complex secondary structures; and [2] what would be the replication efficiency if it can? In this study, we set out to address these two questions by using RCA to replicate a paranemic crossover (PX) DNA molecule.

PX DNA was first reported as a four-stranded DNA complex containing a central dyad axis that relates two flanking parallel double helices. ${ }^{9}$ It has had numerous applications in structural DNA nanotechnology. For example, it has been utilized to construct a DNA octahedron. ${ }^{7}$ Taking advantage of the isomeric transition between $\mathrm{PX}$ and $\mathrm{JX}_{2}$ molecules, a number of robust mechanical DNA devices have been produced. ${ }^{10-11}$ Here, we choose PX DNA as our model replication target for the following two reasons: First, due to the molecule's paranemic nature, it could be produced from two closed dumbbells or even one single circular DNA, ${ }^{9}$ making it a perfect template for RCA. Second, and most importantly, the topology of PX is far more complex than the 4-arm branched DNA junction because it has crossovers at every possible position between the two adjacent double helices. Hence, it provides more challenges for the rolling-circle DNA polymerase to go through the molecule, because it must unwind the multiple closely positioned crossovers if it is to catalyze processive synthesis. This represents the key challenge in replicating artificial DNA nanostructures using RCA. Our results demonstrate that this complicated nano-structure can be efficiently replicated using RCA.

The design of PX DNA replication cycle is schematically illustrated in Figure 1. The initial PX DNA molecule, defined as sense (+) PX, consists of two double helical domains with five crossovers between them. Three ends of the helical domains are capped by $\mathrm{dT}_{4}$ loops and the fourth one is extended to have a nicked 20-mer loop containing a PstI recognition region [d(CTGCAG)] flanking the nick. Such a design allows the PX molecule to be folded from a 160-mer single stranded DNA (ssDNA) and ensures the accessibility of circle-ligase and restriction enzyme to the molecule. The PX molecule is circularized by circle-ligase. The circular PX then serves as the template for RCA. In the presence of $\varphi 29$ DNA polymerase and primer 1, which is complementary to a part of the sense (+) PX sequence, the RCA reaction can proceed and produce a long linear ssDNA containing tandem repeats of the sequence of the anti-sense (-) PX strands. Restriction helper 1, a 15-mer oligonucleotide, is then allowed to hybridize with the RCA product to form cleavable restriction sites for the PstI enzyme. The restriction digestion chops the long RCA product into multiple copies of the individual anti-sense (-) PX, which is the end of the first phase of the replication cycle. To replicate PX molecules with the same sequence as the starting sense (+) PX, a second phase of replication is needed, similar in the procedure as the first phase, 
only with the replacement of primer 1 and restriction helper 1 by their complementary strands, primer 2 and restriction helper 2, respectively.

\section{Material and Methods}

\section{Material}

All DNA strands used (see supplemental material for sequences) were purchased from Integrated DNA Technologies (www.idtdna.com) and purified via denaturing PAGE. The concentrations of the DNA molecules were measured by absorbance at $260 \mathrm{~nm}$. CircLigase $^{\mathrm{TM}}$ and RepliPHI ${ }^{\mathrm{TM}}$ Phi29 DNA polymerase were purchased from Epicentre Technologies Corp (Madison, MI). The restriction enzyme PstI was purchased from New England Biolabs (Ipswich, MA).

\section{RCA Replication of the PX DNA}

\subsection{Circularization of PX DNA}

The sense strand DNA was diluted into $0.2 \mu \mathrm{M}$ in $10 \mu \mathrm{L}$ (or $50 \mu \mathrm{L}$ for the $2^{\text {nd }}$ phase) solution, containing $50 \mu \mathrm{M}$ ATP, $2.5 \mathrm{mM} \mathrm{MnCl}_{2}$ and $5 \mathrm{U} / \mu \mathrm{L}$ CircLigase $^{\mathrm{TM}}$ in $1 \mathrm{x}$ reaction buffer 1 (50 mM MOPS, pH 7.5, $10 \mathrm{mM} \mathrm{KCl,} 5 \mathrm{mM} \mathrm{MgCl}_{2}$ and $\left.1 \mathrm{mM} \mathrm{DTT}\right)$. The reaction was incubated at $60{ }^{\circ} \mathrm{C}$ for $8 \mathrm{hrs}$ and terminated by heating to $80^{\circ} \mathrm{C}$ for $10 \mathrm{~min}$. The solution of the circularized sense DNA was directly used in the following RCA reaction without further purification.

\subsection{RCA Reaction}

The circularized sense strand DNA $10 \mu \mathrm{L}$ (or $50 \mu \mathrm{L}$ for the $2^{\text {nd }}$ phase) was mixed with 6 pmol primer 1 ( 30 pmol primer 2 for the $2^{\text {nd }}$ phase) in $60 \mu \mathrm{L} 1 \mathrm{x}$ reaction buffer $2(40 \mathrm{mM}$ Tris- $\mathrm{HCl}, \mathrm{pH} 7.5,50 \mathrm{mM} \mathrm{KCl}, 10 \mathrm{mM} \mathrm{MgCl} 2,5 \mathrm{mM}\left(\mathrm{NH}_{4}\right)_{2} \mathrm{SO}_{4}$ and $4 \mathrm{mM}$ DTT). To ensure the binding of the primer to the template, an annealing procedure was performed by stepwise cooling at $94{ }^{\circ} \mathrm{C}$ for $5 \mathrm{~min}, 60^{\circ} \mathrm{C}$ for $10 \mathrm{~min}, 45^{\circ} \mathrm{C}$ for $10 \mathrm{~min}$ and $37^{\circ} \mathrm{C}$ for 10 min. After annealing, $2.4 \mu \mathrm{L} 25 \mathrm{mM}$ dNTPs, $0.6 \mu \mathrm{L} 10 \mathrm{mg} / \mathrm{mL}^{\mathrm{BSA}}$ and $500 \mathrm{U}^{\circ e p l i P H I}{ }^{\mathrm{TM}}$ Phi 29 DNA polymerase were added. The RCA reaction was incubated at $37{ }^{\circ} \mathrm{C}$ for $4 \mathrm{hrs}$. The enzyme was then inactivated at $65^{\circ} \mathrm{C}$ for $10 \mathrm{~min}$. The RCA products were ethanol precipitated and re-dissolved in $15.5 \mu \mathrm{L} \mathrm{DI}$ water.

\subsection{Restriction Enzyme Digestion}

The RCA product was hybridized with $15 \mu \mathrm{L} 30 \mu \mathrm{M}$ restriction helper strand $1(25 \mu \mathrm{L} 30$ $\mu \mathrm{M}$ restriction helper 2 for the $2^{\text {nd }}$ phase) in $1 \mathrm{x}$ TAE-Mg buffer (Tris-acetic acid $40 \mathrm{mM}, \mathrm{pH}$ 8.0, magnesium acetate $12.5 \mathrm{mM}$, EDTA $1 \mathrm{mM}$ ) following the stepwise annealing procedure. After annealing, $4 \mu \mathrm{L} 10 \times \mathrm{NE}$ buffer $3(1 \mathrm{M} \mathrm{NaCl}, 500 \mathrm{mM}$ Tris-HCl, $100 \mathrm{mM}$ $\mathrm{MgCl}_{2}$ and $1 \mathrm{mM}$ DTT, New England Biolabs), $0.4 \mu \mathrm{l} 10 \mathrm{mg} / \mathrm{ml} \mathrm{BSA}$ and $1000 \mathrm{U}$ PstI (100 $\mathrm{U} / \mu \mathrm{l})$ were added. The restriction reaction was carried out at $37^{\circ} \mathrm{C}$ for $3 \mathrm{hrs}$ and stopped by heating at $90{ }^{\circ} \mathrm{C}$ for $10 \mathrm{~min}$. The digested product was ethanol precipitated and then redissolved in $37.5 \mu \mathrm{L}$ DI water. This solution is used either for denaturing PAGE analysis/ purification or as the starting material for the second phase of RCA without further purification.

\subsection{Determination of Amplification Factor}

Six parallel one-pot reactions were carried out, each starting from 2 pmol sense (+) PX. After the full replication cycle, the amplified sense (+) PX product was purified by denaturing PAGE. The major band at the expected length was excised, and the DNA products were eluted from the gel, ethanol precipitated and re-dissolved in $40 \mu \mathrm{L}$ water. 
$\mathrm{OD}_{260}$ of the solution was measured. And the amplification factor is thus calculated as $\mathrm{OD}_{260} /$ Ext. Coefficient $* 40 \mu \mathrm{L} / 12 \mathrm{pmol}$.

\section{Characterization of the PX Molecules}

\subsection{Non-denaturing PAGE}

1 pmol each of the original sense (+) PX, the purified final product of the sense (+) PX and a random-sequence 160-mer, were annealed separately in $10 \mu \mathrm{L} \mathrm{1x}$ TAE- $\mathrm{Mg}^{++}$buffer from 94 ${ }^{\circ} \mathrm{C}$ to $25{ }^{\circ} \mathrm{C}$ in 1 hour. The annealed DNA species were resolved by electrophoresis to compare their mobility on an $18 \%$ non-denaturing polyacrylamide gel in $1 \mathrm{x}$ TAE- $\mathrm{Mg}^{++}$ buffer. The gel was run at a constant voltage of $200 \mathrm{~V}$ for $10 \mathrm{hrs,} \mathrm{stained} \mathrm{by} \mathrm{Stains-All}$ (Sigma) and scanned by a desktop scanner (HP scanjet 4670).

\subsection{Melting Temperature Measurement}

The melting of the sense (+) PX, both the original starting material and purified final product ( $80 \mu \mathrm{L}$ of $0.1 \mu \mathrm{M}$ in $1 \mathrm{x}$ TAE-Mg ${ }^{2+}$ buffer), was analyzed in a Cary UV-vis spectrometer using a built-in Peltier temperature control. The $1 \mathrm{x}$ TAE- $\mathrm{Mg}^{2+}$ buffer was used as a blank. Both the samples and the blank were covered and sealed. Absorbance at $260 \mathrm{~nm}$ of the sample was measured while the temperature increased from $25^{\circ} \mathrm{C}$ to $80^{\circ} \mathrm{C}$, in 0.3 ${ }^{\circ} \mathrm{C} / \mathrm{min}$ increments.

\subsection{Ferguson Analysis}

Pre-annealed sense (+) PX, purified final product of sense (+) PX, and a four-stranded PX structure without loops, together with a 25-bp DNA ladder (Invitrogen), were assayed each using $8,12,15,18 \%$ non-denaturing PAGE. The four gels with different gel concentrations were simultaneously run for $3.6 \mathrm{hrs}$ at a constant voltage of $200 \mathrm{~V}$. After staining, the mobility of bands was measured manually using a millimeter-scaled ruler from the gel images.

\section{Hydroxyl Radical Autofootprinting of PX Molecules}

\subsection{Dephosphorylation of 5'-phosphorylated end of DNA}

The sense (+) PX (final product) was 5'-dephosphorylated in $50 \mu \mathrm{L}$ solution containing 20 $\mathrm{mM}$ Tris- $\mathrm{HCl}$ ( $\mathrm{pH} 8.0), 10 \mathrm{mM} \mathrm{MgCl} 2$ and mixed with 5 units of Alkaline Phosphatase for 1 hour at $37^{\circ} \mathrm{C}$. The reaction was stopped by phenol extraction and DNA was purified by ethanol precipitation.

\subsection{Radioactive Phosphorylation}

4 pmol of the replicated DNA was dissolved in $20 \mu \mathrm{L}$ of a solution containing $50 \mathrm{mM}$ Tris$\mathrm{HCl}(\mathrm{pH} 7.6), 10 \mathrm{mM} \mathrm{MgCl}_{2}, 10 \mathrm{mM}$ 2-mercaptoethanol, and mixed with $1 \mu \mathrm{L}$ of $1.25 \mathrm{mM}$ $\gamma^{32} \mathrm{P}$-ATP $(10 \mathrm{mCi} / \mathrm{mL})$ and 2 unit of T4 polynucleotide kinase (USB) for 1 hour at $37^{\circ} \mathrm{C}$. The reaction was stopped by ethanol precipitation of DNA.

\subsection{Hydroxyl Radical Analysis}

The purified final product of sense (+) PX was ${ }^{32} \mathrm{P}$ labeled and additionally gel purified from a $10 \%$ denaturing PAGE. The labeled strand (approximately 2 pmol in $10 \mu \mathrm{L} \mathrm{1x}$ TAE. $\mathrm{Mg}^{2+}$ buffer) was subjected to three different treatments: [1] It was annealed to an excess of the unlabeled complementary strand; [2] it was annealed by itself to form the PX motif; or [3] it was treated with sequencing reagents ${ }^{12}$ for a sizing ladder. The samples were annealed by heating to $90^{\circ} \mathrm{C}$ for $5 \mathrm{~min}$ and then step-wised cooled at $65^{\circ} \mathrm{C}$ for $10 \mathrm{~min}, 45$ ${ }^{\circ} \mathrm{C}$ for $10 \mathrm{~min}, 37^{\circ} \mathrm{C}$ for $10 \mathrm{~min}$, room temperature for $10 \mathrm{~min}$, and $4{ }^{\circ} \mathrm{C}$ for $10 \mathrm{~min}$. 
Hydroxyl radical cleavage of the double-strand and PX motif samples took place at $4{ }^{\circ} \mathrm{C}$ for 2 min, ${ }^{13}$ with modifications noted by Churchill et al. ${ }^{14}$ The reaction was stopped by addition of thiourea. The samples were dried, dissolved in a formamide/dye mixture, and loaded directly on a $12 \%$ polyacrylamide/ $8.3 \mathrm{M}$ urea sequencing gel. Autoradiograms were quantitated using a Storm $860 \mathrm{Gel}$ and Blot Imaging System (Amersham Pharmacia Biotech, Piscataway, NJ).

\section{Results}

\section{Enzymatic Replication of PX DNA}

Properly designed primer is crucial for an efficient replication for DNA nano-objects with complicated secondary structures. We tested the replication efficiency of the first phase of the replication cycle using two primers with 20 or 60 nucleotides. It is noted that the 60 -mer primer provides a better yield of anti-sense (-) PX compared to that of the 20-mer primer (Figure 2a). This is expected because the complexity of the PX structure makes it difficult for $\varphi 29$ polymerase to unwind it and as a consequence, increases the energy barrier of the RCA process. The shorter primer hybridizes only with the 20-mer loop of the sense (+) PX, while the 60-mer primer was designed so that it can partially unwrap the PX complex when hybridizing with the RCA template and thus make the RCA reaction more favorable kinetically. After the first phase of the replication cycle, we can estimate from the gel that approximately five units of anti-sense (-) PX molecules were produced from one unit of sense (+) PX template. Besides the major product, noticeable quantities of DNA species with lower molecular weights were also observed. These by-products are truncated versions of PX, which are most likely generated during the RCA process by bypassing part of the PX template.

It is worth pointing out that all reactions involved in the RCA cycle are sequentially carried out in a "one-pot" manner (i.e. no PAGE purification after any of the steps until the end of the complete circle). Such a protocol eliminates the product loss during DNA elution from gels, thereby leading to an increased overall yield. Figure $2 \mathrm{~b}$ shows three complete RCA cycles in parallel monitored by denaturing PAGE. While the main final product remains the intact sense (+) PX, indicated by the major band with the same mobility as that of the starting material, significant amounts of truncated by-products were produced as well. It is clear that the truncated products represent a higher percentage in the full-cycle products than that in the first phase of RCA. This is expected, because the by-products were not purified away from the reaction mixture after the first RCA phase, and once circularized they, too, can serve as templates for the second phase of RCA. Moreover, they could be amplified more readily than the complete PX molecule, because of their shorter length and reduced structural complexity. Nevertheless, the 160-mer PX strand was efficiently amplified by about 40 times (estimated from the band intensities in the gel image) after one full cycle of RCA replication, and the existence of oligomeric versions of PX (ladder patterned bands with lower mobility) suggests that the yield can be improved further by optimizing the restriction digestion conditions. In another batch of replication, 146 pmols of sense (+) PX was obtained from $12 \mathrm{pmol}$ initial template after a complete replication cycle and following PAGE purification, leading to a net amplification factor $\sim 12$. It is important that the amplification is not limited to one round of cycling. In fact, our replication strategy can be regarded as an RCA chain reaction since there are cross-replications between the sense and anti-sense structures. In theory, the amplification factor increases exponentially when the number of replication cycles is increased. 


\section{Characterization of PX Molecules}

Three experiments were performed to test the correct folding of the amplified PX structure. First, we assayed the purified final product using non-denaturing PAGE (Figure $3 \mathrm{a}$ ). The annealed PX strands, both starting material and purified final product, and a randomsequence 160-mer oligonucleotide, were loaded into an $18 \%$ non-denaturing polyacrylamide gel and resolved by electrophoresis. The replicated PX structure and the starting PX have exactly the same mobility on the gel, each represented by a sharp clean band, indicating that they folded into the same well-behaved secondary structure. Furthermore, both migrated faster than random-sequence ssDNA of the same length, suggesting their compactly folded structures. Second, thermal transition analysis (Figure 3b) indicates that the PX molecules after amplification show thermal transition behavior similar to that of the starting material, with a melting temperature of approximately $69^{\circ} \mathrm{C}$. Note that because the concentration of PX molecules used in this experiment was low $(0.1 \mu \mathrm{M})$, the pre-melting features are slightly different, possibly due to noise during the measurement. The third piece of evidence for the formation of PX structures comes from Ferguson analysis, which provides information about the molecular shape and surface area. As seen in the Ferguson plots (Figure 3c), the data points for the sense (+) PXs, both before and after amplification, overlap in the plot and they display a similar slope to that of a PX molecule composed of the same core structure but lacking the loop. In contrast, the plot for a 125-bp double helical molecule exhibited a significantly different slope. Moreover, the slopes of the PX molecules observed here are highly consistent with former studies by Shen et al $(\sim-0.093) .{ }^{9}$ These data strongly suggest that we have correctly replicated the PX structure as designed.

\section{Hydroxyl Radical Analysis}

Churchill et al. ${ }^{14}$ first analyzed the structure of branched DNA species in solution by means of hydroxyl radical autofootprinting experiments, in which the hydroxyl radicals have been generated by Fenton chemistry involving Fe(II)EDTA ${ }^{2-} .{ }^{13,15}$ This is a very powerful technique, because it gives single-nucleotide resolution of nucleotide susceptibility to the attack of hydroxyl radicals. A quantitative pattern of backbone cleavage at all possible sites can be produced. The strategy of such experiments is to compare the chemical attack pattern of each strand when it is part of an unconventional species, with the pattern obtained when the strand is fully hybridized with its normal Watson-Crick complement. ${ }^{16}$ Experiments with 4-arm junctions indicate that the patterns of two non-contiguous strands are the same in both environments, while the other two strands, those that cross over at the branch point, exhibit protection at the site of the junction. From those experiments it was concluded that strands with the same patterns in both pairing environments probably have double helical conformations near the junction, while the other strands form crossover structures. ${ }^{14}$ Similarly, the hydroxyl radical protection patterns of PX molecules have indicated that there are crossovers at the exact sites where they are designed to be. ${ }^{9}$

Thus, the autofootprinting pattern of the purified product after the full cycle of RCA was determined, to establish that molecule indeed forms the PX structure. Figure 4 shows the pattern of the single-stranded molecule ('PX') compared with the pattern of the same strand in a duplex context ('DS'). The raw patterns are illustrated in Figure 4a, and the results are summarized on a molecular schematic on the left side of Figure $4 \mathrm{~b}$. The right side of Figure $4 \mathrm{~b}$ shows an image that emphasizes the presence of major and minor grooves in the molecule. Protection is noted for each of the nucleotides flanking the expected crossover points in the molecule. Sometimes, the nucleotide 5 ' to this pair is also protected, a result commonly seen in branched species. ${ }^{9}, 14$ These data show clearly that the PX structure has conserved through the RCA reactions. 


\section{Discussion}

We have succeeded in replicating a structurally complex DNA nano-structure using enzymatic methods. The strategy is conceptually straightforward and technically easy, yet provides excellent replication efficiency. The correct replication of PX DNA not only increases the complexity limit of DNA nano-structures that can be replicated by RCA, but also suggests the possibility of amplifying self-assembled DNA nanoarrays that contain multiple crossovers between double helical domains. For example, by extending PX molecule with half PX "sticky ends", one could design replicable 2D nanoarrays assembled from single stranded PX tiles. It is expected the one could use the strategy described here to scale up the construction of DNA based nanoconstructions, which is now limited by the chemical synthesis scale of oligonucleotides. In the future, it would be also interesting to replicate DNA structures with more complicated topologies such as single stranded knots. ${ }^{17}$

The success in enzymatically replicating DNA nano-structures makes one wonder if it is possible to clone nano-structures using viruses and cells. Evolution over billions of years has enabled viruses to infect their host cells and then to replicate themselves. Modern molecular biologists have exploited this elegant "natural molecular assembly line" and developed recombinant DNA and cloning techniques. For example, human DNA fragments can be cloned within a viral vector. ${ }^{18}$ Moreover, a number of virus DNA molecules are single stranded (e.g. M13), making it compatible with our one-stranded nano-structure design. Inspired by this, we suggest that it is possible to clone complicated DNA nano-structures in vivo. Figure 5 illustrates one of the possible schemes, related to an earlier suggestion. ${ }^{19}$ The PX DNA strand is incorporated into a viral DNA and then delivered to the cell when the virus infects its bacteria host. Thus, as the "PX engineered" viral DNA replicates, the PX molecule is cloned as well. After simple post-processing, including phage DNA extraction and restriction digestion, this strategy could ultimately lead to high copy numbers of PX molecules, produced from a single one. Although the overall efficiency of in-vitro RCA replication of multi-crossover DNA structure is relatively low, in vivo proteins such as helicases may facilitate this process.

\section{Supplementary Material}

Refer to Web version on PubMed Central for supplementary material.

\section{Acknowledgments}

This research has been supported by grants CTS-0545652, CCF-0453685, CTS-0609362, DMR-0709938, CCF-0727100 from the NSF, N00014-07-1-0194 from ONR and FA9550-07-1-0080 from AFSOR, 1R21 EB0005844-01 from the NIH and fundings from Arizona State University to H.Y., and by grants GM-29554 from NIGMS, grants DMI-0210844, EIA-0086015, CCF-0432009, CCF-0523290 and CTS-0548774, CTS-0608889 from the NSF, 48681-EL from ARO, DE-FG02-06ER64281 from DOE (Subcontract from the Research Foundation of SUNY), and a grant from the W.M. Keck Foundation, to N.C.S. and C06 RR-16572-01 from NCRR to NYU. We thank Prof. Jiunn-Liang Chen for helpful discussions and Mingyi Xie for technical assistance in DNA purification.

\section{References}

1. Seeman NC. Nature. 2003; 421:427-431. [PubMed: 12540916]

2. Lin C, Liu Y, Rinker S, Yan H. ChemPhysChem. 2006; 7:1641-1647. [PubMed: 16832805]

3. Feldkamp U, Niemeyer CM. Angew Chem Int Ed. 2006; 45:1856-1876.

4. Deng ZX, Lee SH, Mao CD. Journal of Nanoscience and Nanotechnology. 2005; 5:1954-1963. [PubMed: 16430130]

5. Turberfield AJ. Phys World. 2003; 16:43-46. 
6. Eckardt LH, Naumann K, Pankau WM, Rein M, Schweitzer M, Windhab N, von Kiedrowski G. Nature. 2002; 420:286. [PubMed: 12447432]

7. Shih WM, Quispe JD, Joyce GF. Nature. 2004; 427:618-621. [PubMed: 14961116]

8. Lin C, Xie M, Chen JJL, Liu Y, Yan H. Angew Chem Int Ed. 2006; 45:7537-7539.

9. Shen Z, Yan H, Wang T, Seeman NC. J Am Chem Soc. 2004; 126:1666-1674. [PubMed: 14871096]

10. Yan H, Zhang X, Shen Z, Seeman NC. Nature. 2002; 415:62-65. [PubMed: 11780115]

11. Ding B, Seeman NC. Science. 2006; 314:1583-1585. [PubMed: 17158323]

12. Maxam AM, Gilbert W. Proc Natl Acad Sci USA. 1977; 74:560-564. [PubMed: 265521]

13. Tullius TD, Dombroski B. Science. 1985; 230:679-681. [PubMed: 2996145]

14. Churchill MEA, Tullius TD, Kallenbach NR, Seeman NC. Proc Natl Acad Sci USA. 1988; 85:4653-4656. [PubMed: 3387432]

15. Tullius TD, Dombroski B. Proc Natl Acad Sci USA. 1986; 83:5469-5473. [PubMed: 3090544]

16. Seeman, NC. Curr Protocols Nucl Acid Chem. John Wiley \& Sons; New York: 2002.

17. Seeman NC. Molecular Engineering. 1992; 2:297-307.

18. Berg, P.; Singer, M. Dealing with Genes: The language of Heredity. University Science Books; Mill Valley, California: 1992.

19. Seeman NC. DNA \& Cell Biol. 1991; 10:475-486. [PubMed: 1892564] 

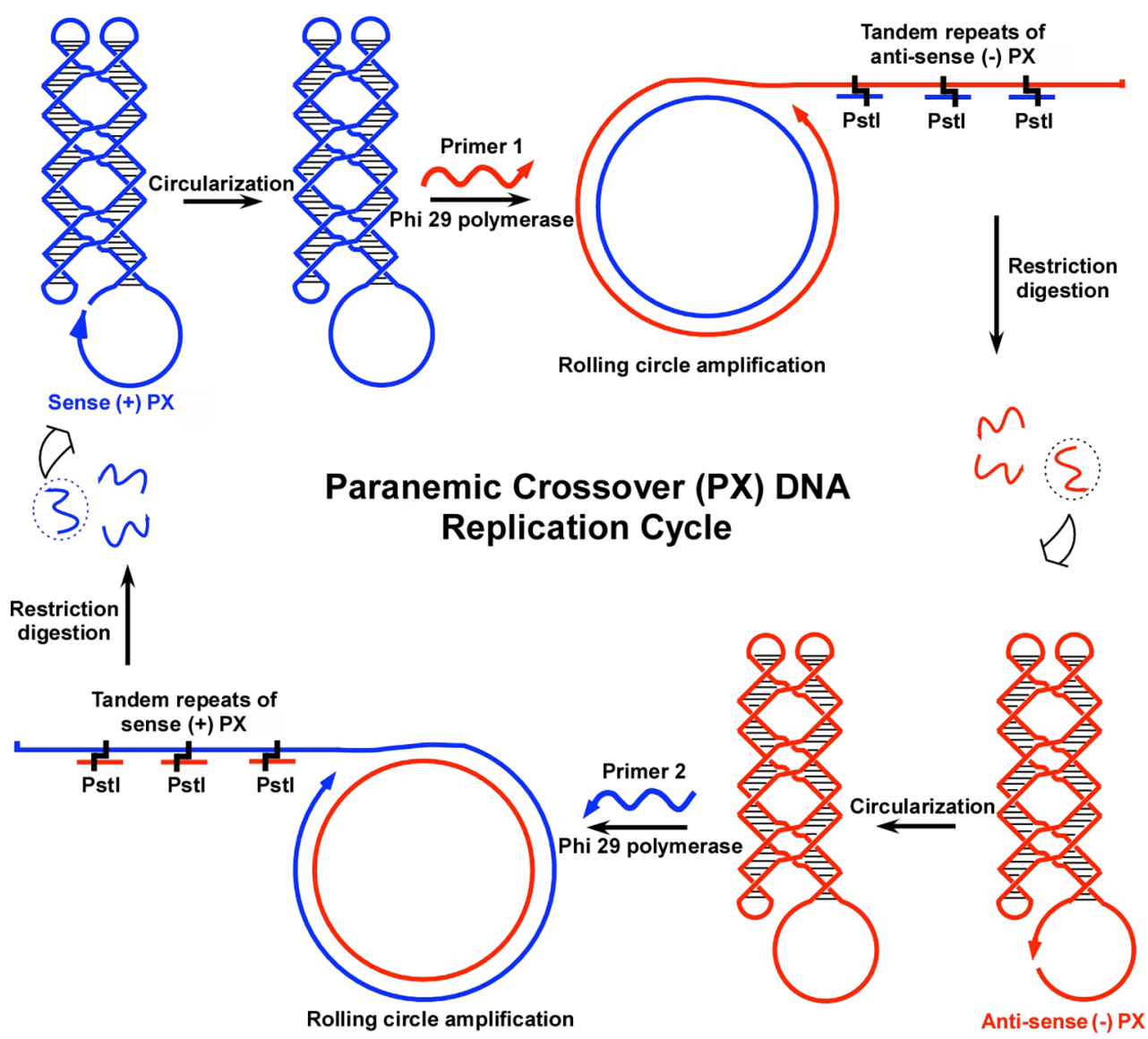

Figure 1.

Schematic of paranemic crossover DNA replication cycle. 
a)

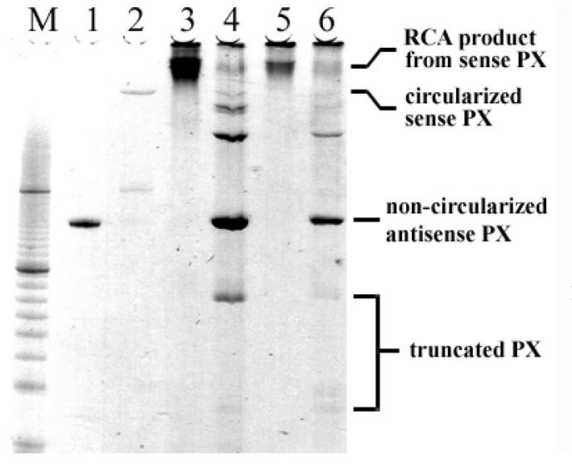

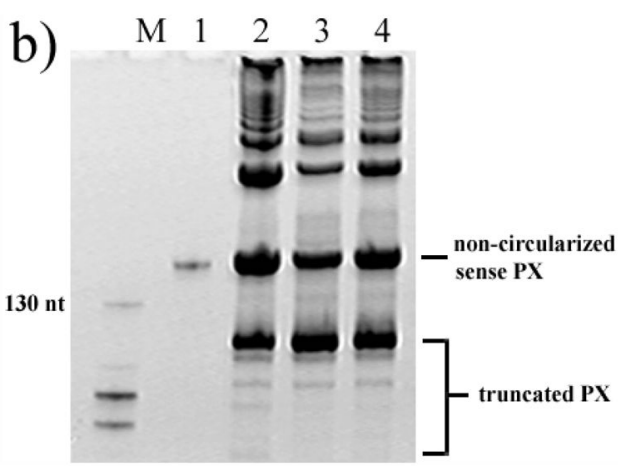

Figure 2.

Evaluation of the amplification efficiency by $10 \%$ denaturing PAGE. a) The first phase of the RCA cycle. Lane M: 20-bp DNA ladder; lane 1: 2 pmol linear sense (+) PX; lane 2: after circle-ligation; lane 3 and 4: after RCA using 60-mer primer and subsequent PstI digestion; lane 5 and 6: after RCA using 20-mer primer and subsequent PstI digestion. Lanes 2-6 each contain products started from $2 \mathrm{pmol}$ sense (+) PX. 5-fold amplification (using 60-mer primer) was estimated from the gel image. b) The complete "one-pot" RCA cycle. Lane M: 10-nt ssDNA ladder; lane 1: 2 pmol linear sense (+) PX; lanes 2-4: final products after the full "one-pot" replication cycle. These are parallel reactions: Each contains products starting from 2 pmol sense (+) PX, without PAGE purification after any steps. An average of $\sim 40$ fold-amplification was estimated from the gel image. 

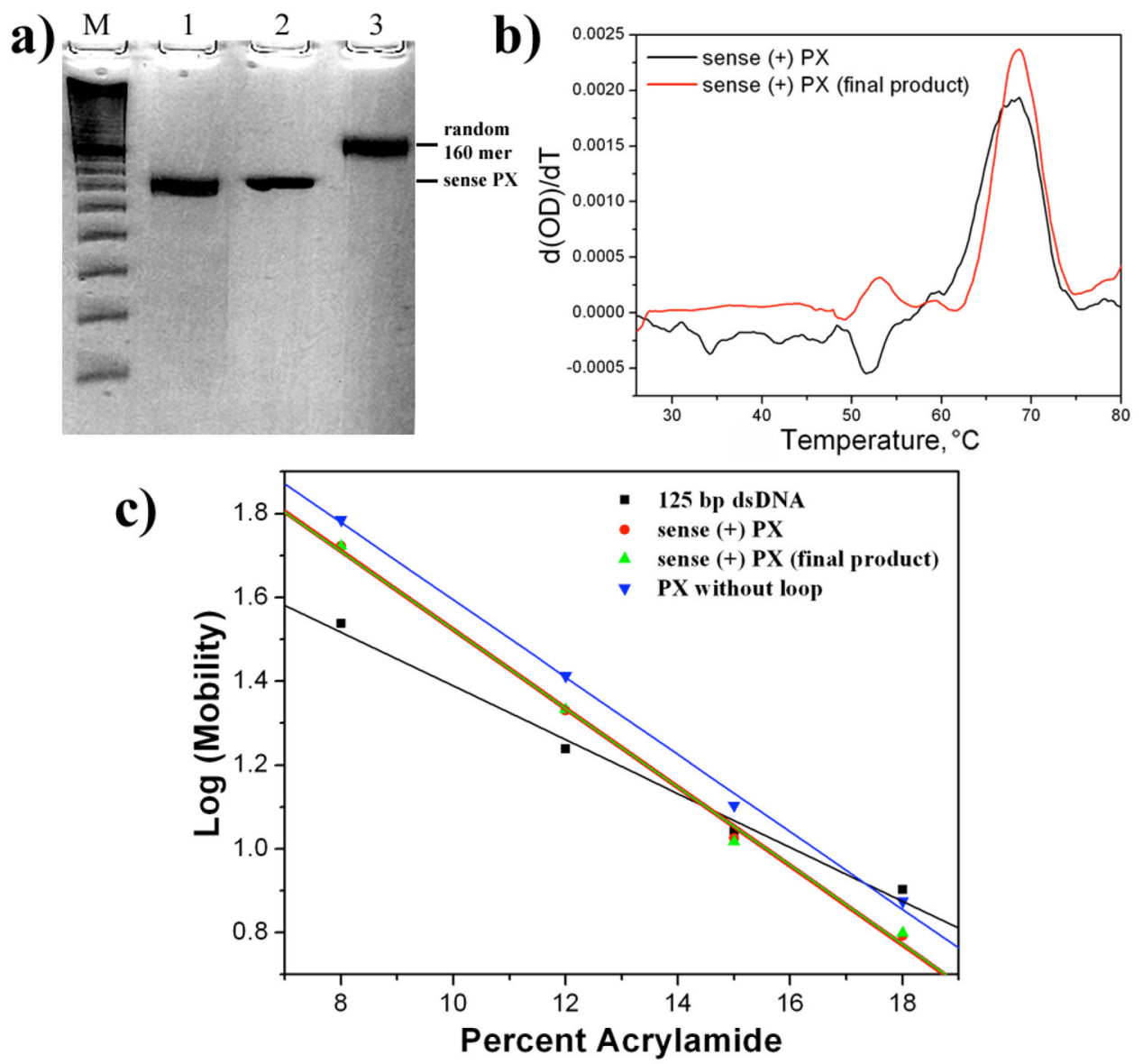

Figure 3.

Characterization of the PX structures. a) 18\% Non-denaturing PAGE analysis. Lane M: 20bp DNA ladder; lane 1: annealed starting sense (+) PX; lane 2: annealed purified final product after the full cycle; lane 3: annealed 160-mer oligonucleotide with a random sequence. b) Differential melting curves. The sense (+) PXs, both starting material and final product, show similar thermal transition behavior with $\mathrm{Tm} \approx 69^{\circ} \mathrm{C}$. c) Ferguson study of $\mathrm{PX}$ structures. The plots of the sense (+) PX (red) and the final product (green) are compared with a PX molecule with the same core structure but without loop (blue) and a 125-bp double stranded DNA (dsDNA, black). Slopes: -0.0940 (sense (+) PX), -0.0938 (final product), -0.0922 (PX without loop) and -0.0641 (dsDNA). 
(a)

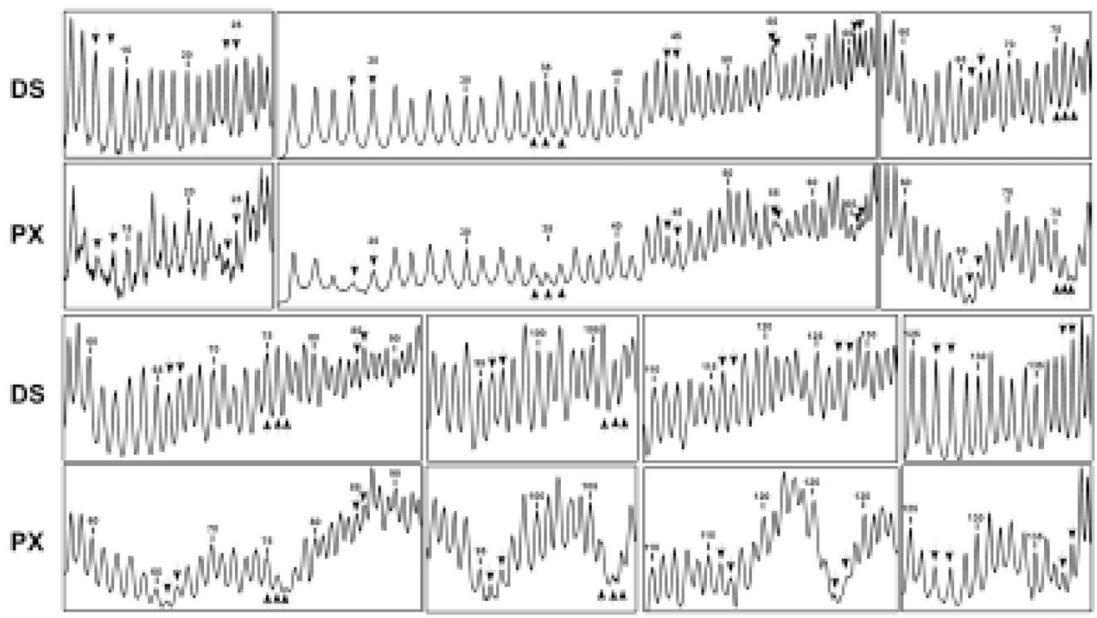

(b)

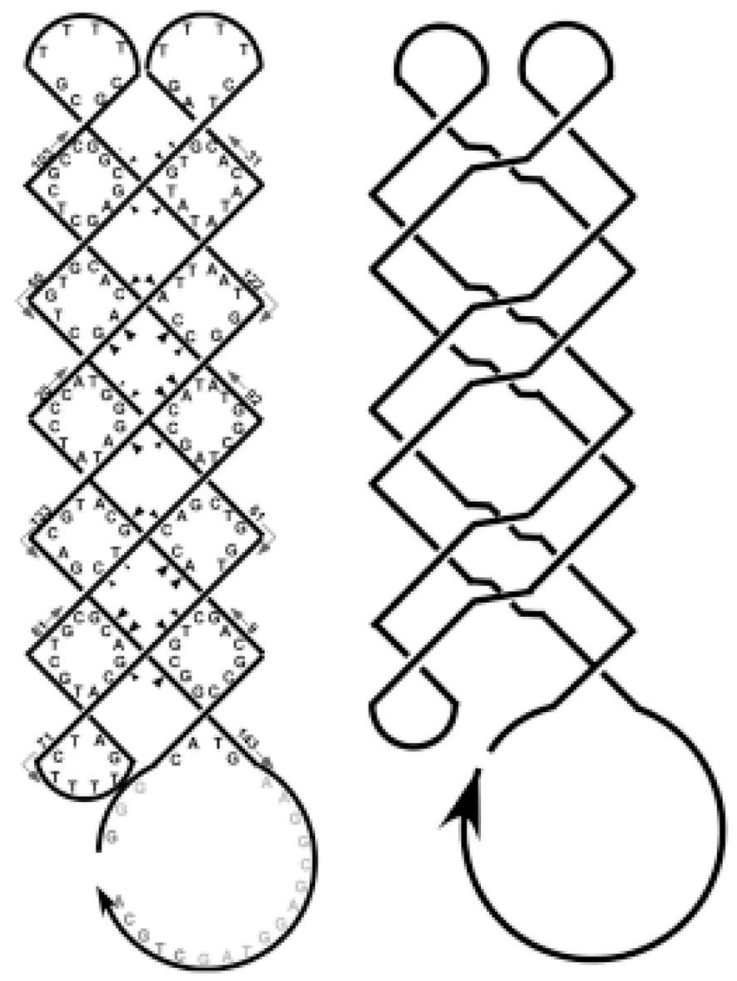

Figure 4. Hydroxyl Radical Autofootprinting of the Structure Produced by RCA

a) Hydroxyl Radical Chemical Attack Patterns. Double stranded patterns are labeled as 'DS' and the folded single strands are labeled as 'PX'. These plots are quantitative scans of gels showing the extent of cleavage of the indicated strands by hydroxyl radicals. The positions are numbered from the 5 ' ends, at every fifth position. The nucleotides flanking expected crossovers are indicated by a pair of downward pointing arrows. Hairpins are labeled by upward pointing triplets of arrows. Each nucleotide expected to flank a junction in the PX pattern shows decreased cleavage relative to the same nucleotide in the DS pattern. b) Schematics of the Cleavage Pattern. The left drawing shows the positions of relative cleavage protection as triangles pointing at the nucleotide. The size of the triangle is a qualitative indication of the protection. Protection at the hairpins is not indicated. Strand numbering is shown and strand polarity is indicated by small arrows emanating from those 
numbers. Note that the cleavage protection positions all flank crossovers. The right drawing shows a schematic somewhat closer to the molecular structure, because it indicates the major and minor grooves. 


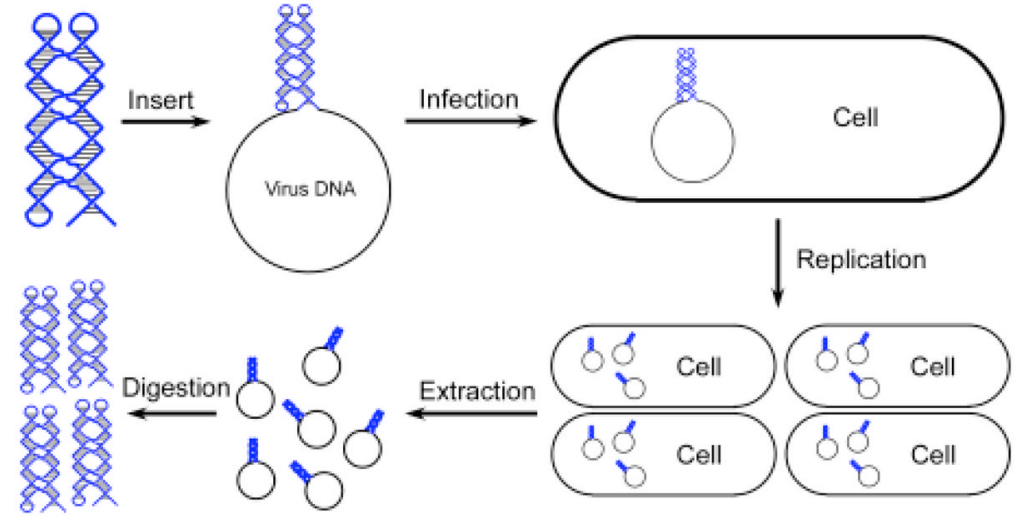

Figure 5.

Schematics showing the possible cloning of PX structure in cells. 